\title{
Methods employed to assess left ventricular ejection fraction in patients referred for cardiac resynchronization therapy in Poland as compared to other European countries. Results from European Cardiac Resynchronization Therapy Survey II
}

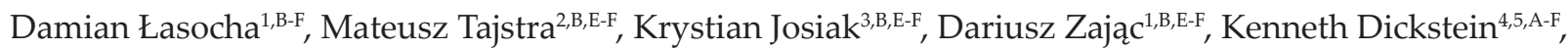 \\ Cecilia Linde $^{6, \mathrm{~A}-\mathrm{F}}$, Camilla Normand ${ }^{4,5, \mathrm{~A}-\mathrm{F}}$, Łukasz J. Szumowski ${ }^{1, \mathrm{C}, \mathrm{E}-\mathrm{F}}$, Maciej Sterliński ${ }^{1, \mathrm{~A}-\mathrm{F}}$ \\ A - Research concept and design, B - Collection and/or assembly of data, C - Data analysis and interpretation, \\ D - Writing the article, E - Critical revision of the article, F - Final approval of article \\ 1 National Institute of Cardiology, Warsaw, Poland \\ 2 Faculty of Medical Sciences in Zabrze, Medical University of Silesia in Katowice, Poland \\ 3 Wrocław Medical University, Wrocław, Poland \\ 4 Cardiology Division, Stavanger University Hospital, Stavanger, Norway \\ 5 Institute of Internal Medicine, University of Bergen, Bergen, Norway \\ 6 Karolinska University Hospital and Karolinska Institute, Stockholm, Sweden
}

Address for correspondence:

Maciej Sterliński, National Institute of Cardiology, Warsaw, Poland email: msterlinski@poczta.onet.pl

Received: 2019-12-29

Revised:

Accepted: 2019-12-30

Final review:

DOI: $10.24255 / \mathrm{hbj} / 100629$

\begin{abstract}
Background

Precise evaluation of left ventricular ejection fraction (LVEF) $35 \%$, i.e. an indication outside of the guidelines, was found in $15.9 \%$ of PL (Polish) patients vs. 24.2\% of OEC (other European countries) patients $\left(\mathrm{p}^{*}\right)$. LVEF $>50 \%$ was found in $0.8 \%$ and $1.9 \%$ of patients respectively $\left(\mathrm{p}^{*}\right)$. Concerning methodology, echocardiography was used in $99.2 \%$ of PL and $97.5 \%$ of OEC patients $\left(\mathrm{p}^{*}\right)$. Other imaging tools such as cardiac MRI, CT and scintigraphy were used in $2.2 \%$ vs $16.7 \%\left(\mathrm{p}^{*}\right)$, and in $1.4 \%$ and $14.2 \%$ respectively $\left(\mathrm{p}^{*}\right)$ more than one method was used.
\end{abstract}

\section{Conclusions}

Echocardiographic LVEF measurement is the most frequent diagnostic tool both in Poland and OEC. Other methods such as cardiac MRI, CT and scintigraphy or multiple methods were more common in OEC than in Poland. CRT implantations, both in PL and OEC, are performed in a significant proportion of patients with LVEF $>35 \%$.

Key words:

cardiac resynchronization therapy, imaging, echocardiography, left ventricular ejection fraction 


\section{Abstract}

Precise evaluation of left ventricular ejection fraction (LVEF) $<35 \%$ is a crucial guideline indication criterion for implanting cardiac resynchronization therapy (CRT) in patients with congestive heart failure $(\mathrm{HF})$. We present the data from 1241 Polish (PL) patients and 9847 patients from other European countries (OEC) (aged: $67.7 \pm 9.7$ and $68.6 \pm 10.9$, ns, M/F: $81.3 \% / 18.7 \%$ and $75 \% / 25 \%$ respectively, $\mathrm{p}^{*}$ stands for statistical significance) with their LVEF and the measuring methods used in the European CRT Survey II database. Mean LVEF in CRT recipients was $26.4 \pm 8.0 \%$ vs. $28.7 \pm 8.1 \%$. LVEF $>35 \%$, i.e. an indication outside of the guidelines, was found in $15.9 \%$ PL patients vs. $24.2 \%$ in OEC patients ( $\mathrm{p}^{*}$ ).
LVEF $>50 \%$ was found in $0.8 \%$ and $1.9 \%$ of patients respectively $\left(\mathrm{p}^{*}\right)$. Concerning methodology echocardiography was used in $99.2 \%$ of PL and $97.5 \%$ of OEC patients $\left(p^{*}\right)$. Other imaging tools such as cardiac MRI, CT and scintigraphy were used in $2.2 \%$ vs $16.7 \%\left(\mathrm{p}^{*}\right)$, and in $1.4 \%$ and $14.2 \%$ respectively $\left(p^{*}\right)$ more than one method was used.

Echocardiographic LVEF measurement is the most frequent diagnostic tool both in Poland and OEC. Other methods such as cardiac MRI, CT and scintigraphy or multiple methods were more common in OEC than in Poland. CRT implantations, both in PL and OEC, are performed in a significant proportion of patients with LVEF > 35\%.

\section{Introduction}

Precise evaluation of left ventricular ejection fraction (LVEF) is considered to be a crucial part of qualification for cardiac resynchronization therapy (CRT) in patients with congestive heart failure (HF). Current guidelines recommend CRT with defibrillation function (CRT-D) in patients with LVEF depressed to less than or equal to $35 \%$ and pacing-only units (CRT-P) additionally in HF patients with reduced LVEF, expected to depend on RV pacing ${ }^{[1]}$. Echocardiography is suggested as a preferred method of LVEF assessment. Analysing sub-group data collected in the COMPANION, CAREHF, MADIT-CRT, REVERSE, and RAFT trials proved that despite severely depressed LVEF (less than or equal to 35\%), CRT improves outcome for heart failure patients (NYHA IIIV) with complete left bundle branch block (LBBB) and QRS duration greater than or equal to $150 \mathrm{~ms}^{[2]}$. Therefore, current European Society of Cardiology (ESC) guidelines provide strong recommendations for CRT in patients who do not respond sufficiently to medical therapy. Analysing the data from registry surveys - such as the recently terminated European Cardiac Resynchronization Therapy Survey II - allows physicians to compare their practice with the guidelines and with international practice ${ }^{[3,4]}$.

As far as imaging modalities are concerned, both ESC guidelines on cardiac pacing and cardiac resynchronization therapy and ESC guidelines for the diagnosis and treatment of acute and chronic heart failure recommend echocardiography as a method of choice to assess LVEF in patients with suspected $\mathrm{HF}^{[5]}$. However, echocardiography may exaggerate LV dysfunction, as evidenced when clinicians' results were re-evaluated by core labs ${ }^{[6]}$. Moreover, in certain clinical conditions echocardiography may or should be complemented by other imaging methods such as cardiac MRI, CT scan or scintigraphy ${ }^{[7]}$.

\section{Aim}

To compare imaging methods, LVEF values and their distribution in patients in Poland and in other European countries (OEC), indicated for CRT implantation.

\section{Methods and study population}

In 2015-2107 the European Cardiac Resynchronization Therapy Survey II was led by the European Heart Rhythm Society (EHRA) and Heart Failure Association (HFA), designed to collect the large volume of clinical and demographic data of CRT practice in member nations of the European Society of Cardiology (ESC) and divided here into Poland (PL) and OEC for simplification (though some of them are not in geographical Europe $)^{[3,4]}$. The results allow each parameter such as either demographic data or procedural information from one county to be compared to all other remaining countries, thus permitting centres and countries to benchmark their own practice with international practice. An important section of the collected data was the indications for CRT implantation according to current ESC guidelines, including LVEF assessment data. The methods and the main findings of the CRT Survey II have been published ${ }^{[3,4]}$. However, the methods and results of LVEF measurements have not been specifically addressed.

Data collection, management, analyses and statistical methods

The web-based eCRF used for data collection was developed by Institut für Herzinfarktforschung Ludwigshafen (IHF), which also conducted data management and statistical analyses ${ }^{[8]}$. All percentages are relative to the total number of patients with available information. Median and interquartile (IC) ranges are given. Statistical significance of compared results is marked by $\mathrm{p}^{*}$, non-significance by ns.

\section{Results}

Survey data were obtained from 288 hospitals from 42 countries, involving a total of 11088 patients. Poland was the greatest contributor and included 1241 patients, which was the largest cohort, representing $11.2 \%$ of the entire survey.

\section{Euro CRT Survey II Polish arm contributors list (inclusions} per site order):

Mariusz Gąsior (Zabrze); Piotr Ponikowski, Dariusz Jagielski (Wrocław); Hanna Szwed, Mariusz Pytkowski (Warszawa); Andrzej Przybylski (Rzeszów); Zbigniew Kalarus (Zabrze); Grzegorz Opolski (Warszawa); Krzysztof S. Gołba, Jacek 
Wilczek (Katowice); Stefan Grajek, Przemysław Mitkowski, Lidia Michalak (Poznań); Dariusz Wojciechowski (Warszawa); Paweł Czaja (Kalisz); Grzegorz Raczak, Maciej Kempa, Szymon Budrejko (Gdańsk); Andrzej Skrobowski, Zbigniew Orski (Warszawa), Marianna Janion, Anna Polewczyk (Kielce); Wojciech Gnyp, Marek Ujda, Jerzy Ozga (Stalowa Wola); Hubert Krupa (Polanica Zdrój); Barbara Pankiewicz, Bogusław Grzegorzewski (Chorzów); Ryszard Grzywna (Lublin); Paweł Jesionowski, Piotr Anders (Zielona Góra); Jerzy Górny, Tomasz Godlewski (Olsztyn); Dorota Kołodziejska, Marmak (Łęczyca); Jacek Lelakowski, Justyna Piekarz (Kraków); Robert Gil, Dari-

\section{Patients in the Polish and OEC cohorts}

Baseline demographic and clinical characteristics of Polish and other European countries subgroups are shown in Table 1. usz Kosior, Karol Król (Warszawa); Grzegorz Skonieczny (Toruń); Jerzy Krzysztof Wranicz, Krzysztof Kaczmarek (Łódź); Tomasz Sodolski (Lublin); Katarzyna Mizia-Stec, Wojciech Kwaśniewski (Katowice); Aleksander Goch, Bartosz Topoliński (Bydgoszcz); Antoni Przyprawa (Krosno); Artur Oręziak (Warszawa); Krystyna Łoboz - Grudzień, Mateusz Kuśmierz (Wrocław); Krzysztof Turuk, Adam Gorlo (Augustów), Paweł Miękus, Elżbieta Dułak (Gdynia); Zbigniew Kiedrowicz, Mariusz Nowakowski (Słupsk); Marek Szołkiewicz, Roman Moroz (Wejherowo); Roman Szełemej, Ryszard Serafin (Wałbrzych)

As can be seen, more patients in Poland received a CRT-D, were in sinus rhythm and had a previous device.

\begin{tabular}{|c|c|c|c|}
\hline & Poland & All other countries & $p$ \\
\hline No. of patients & 1241 & 9847 & \\
\hline \multicolumn{4}{|l|}{ Demographics } \\
\hline Age [years] & $67.7 \pm 9.7$ & $68.6 \pm 10.9$ & ns \\
\hline \multicolumn{4}{|l|}{ Gender } \\
\hline Male/Female & $81.3 \% / 18.7 \%(1002 / 231)$ & $75.0 \% / 25.0 \%(7364 / 2455)$ & $p^{*}$ \\
\hline \multicolumn{4}{|c|}{ Primary HF aetiology } \\
\hline Ischaemic & $58.5 \%(722 / 1234)$ & $42.7 \%(4153 / 9719)$ & $p^{*}$ \\
\hline Non-ischaemic & $39.9 \%(492 / 1234)$ & $51.0 \%(4961 / 9719)$ & $p^{*}$ \\
\hline Other & $1.6 \%(20 / 1234)$ & $6.2 \%(605 / 9719)$ & $p^{*}$ \\
\hline \multicolumn{4}{|c|}{ Pre-implant clinical evaluation } \\
\hline Previous device & $30.7 \%(378 / 1232)$ & $27.5 \%(2681 / 9760)$ & $p^{*}$ \\
\hline \multicolumn{4}{|l|}{ NYHA class } \\
\hline । & $0.9 \%(11 / 1230)$ & $3.7 \%(359 / 9618)$ & $p^{*}$ \\
\hline ॥ & $38.3 \%(471 / 1230)$ & $37.6 \%(3612 / 9618)$ & ns \\
\hline III & $58.3 \%(717 / 1230)$ & $54.0 \%(5192 / 9618)$ & $p^{*}$ \\
\hline IV & $2.5 \%(31 / 1230)$ & $4.7 \%(455 / 9618)$ & $p^{*}$ \\
\hline \multicolumn{4}{|l|}{ Leading rhythm } \\
\hline Sinus & $70.1 \%(861 / 1228)$ & $69.1 \%(6635 / 9608)$ & ns \\
\hline Atrial fibrillation & $24.3 \%(299 / 1228)$ & $25.8 \%$ (2479/9608) & ns \\
\hline Atrial paced & $3.5 \%(43 / 1228)$ & $2.7 \%(260 / 9608)$ & ns \\
\hline Other & $2.0 \%(25 / 1228)$ & $2.4 \%(234 / 9608)$ & ns \\
\hline \multicolumn{4}{|c|}{ Succesfully implanted devices } \\
\hline CRT-P/CRT-D & $13 \% / 87 \%(155 / 1037)$ & $32.4 \% / 67.6 \%(3101 / 6476)$ & $p^{*}$ \\
\hline
\end{tabular}




\section{Methodology for LVEF assessment}

Percentages of echocardiography, cardiac MRI, CT scan and scintigraphy used for LVEF determination are shown in Figure 1 . In $1.4 \%$ and in $14.2 \%$ respectively $\left(\mathrm{p}^{*}\right)$ more than one method has been used to confirm the LVEF value. Scar evaluation by any method to adjust optimal LV lead placement was used in 1.8\% (22/1230) in the Polish group vs 3.1\% $(299 / 9540)\left(p^{*}\right)$ in the OEC cohort.

$$
p^{*}
$$

Poland; ECHO; 99,2\%
Poland

All other countries

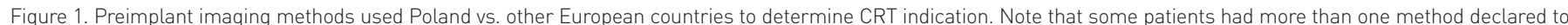
assess LVEF.

Abbreviations: MRI - magnetic resonance imaging,

CT - computed tomography

CRT - cardiac resynchronization therapy, ECHO - echocardiography, LVEF - left ventricular ejection fraction.

p* Abbreviations wszystkie w jednej linii razem z tymi co sạ na górze, alfabetycznie A potem p* (mała litera) - stands for statistical significance

\section{Results of LVEF measurements}

In the Polish vs. OEC population mean LVEF determining CRT indication was $26.4 \pm 8.0 \%$ vs. $28.7 \pm 8.1 \%$, median: $25 \%$ $(20,30)$ vs. $30 \%(24,34)$. There were no patients with LVEF lower than $10 \%$. LVEF > $35 \%$ was recorded in $15.9 \%$ vs. $24.2 \%$ of patients in Poland and in OEC; in this subgroup LVEF greater than or equal to $50 \%$ was found in $0.8 \%$ and $1.9 \%$ of patients respectively $\left(\mathrm{p}^{*}\right)$. LVEF value distribution with $\mathrm{p}$ for compartments is shown in Figure 2. 


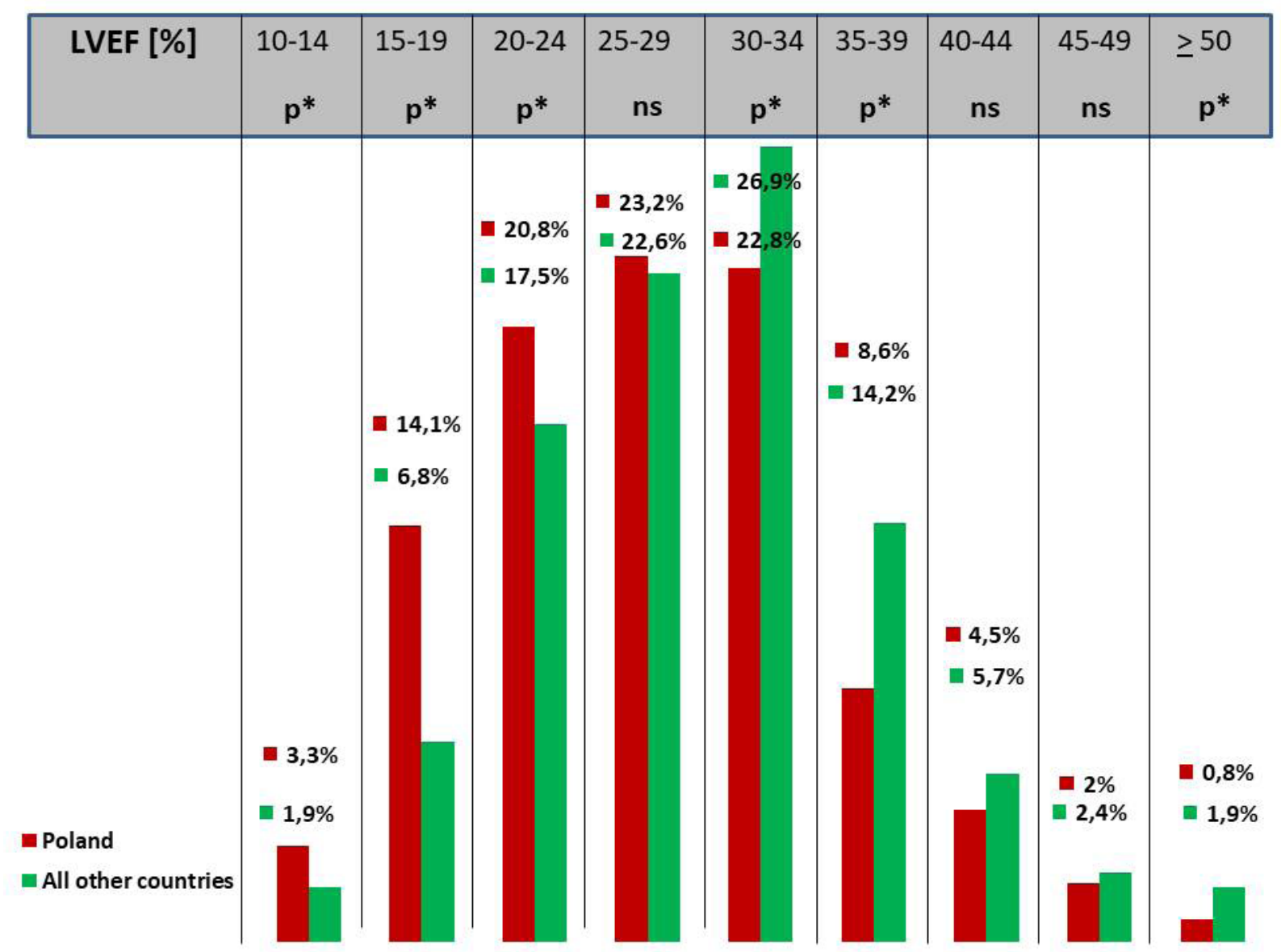

Figure 2. Values of left ventricular ejection fraction estimated by any method in patients qualified for cardiac resynchronization therapy in Poland vs. other European countries

Abbreviations: LVEF - left ventricular ejection fraction

$\mathrm{P}^{*}$ stands for statistical difference, ns - statistical non-significance

\section{Discussion}

Guidelines base their indications for CRT on results of randomized trials and the inclusion criteria applied in these studies. However, patients in randomized trials are often younger and healthier than HF patients in the community. Therefore the survey data better reflect how the guidelines are used in clinical practice. Data from European CRT Survey II bring much important knowledge on actual national practice with reference to the average European background ${ }^{[9,10]}$. Focusing on imaging methods, echocardiography is the method most commonly used to estimate LVEF all over Europe, thanks to its availability, ease of use, safety, low cost and potential accuracy. Nevertheless, echocardiographic results may vary over time and between investigators and confirmation by other diagnostic tools seems reasonable for providing such complex treatment as $\mathrm{CRT}^{[11,12]}$. In patients with ischemic heart disease such methods may help in localizing scar tissue, thus indicating areas to avoid as regards left ventricular lead placement. There was a significant difference between Poland and OEC in use of additional imaging modalities, especially cardiac MRI, and in application of more than one method to determine LVEF. This difference cannot be explained by the organizational and financial aspects only, as the availability of radiology methods in cardiology increased visibly in Poland over the last decade, and this fact is worth emphasizing.

Regarding LVEF values, a greater proportion of patients in Poland than in OEC had LVEF $<35 \%$. Likewise a LVEF $>$ $35 \%$ was found in $15.9 \%$ in the Polish vs. $24.2 \%$ of patients in the OEC cohort. Those results may account for the proportion of the clinical indication for CRT-P in LVEF depressed HF patients, such as subjects who are dependent on RV pacing or scheduled to undergo His ablation, which is supported by current guideline ${ }^{[1]}$. Surprisingly, 195 patients out of the whole survey population underwent off-label CRT implantation since LVEF was $>50 \%$.

In recent years, long-term LVEF performance and CRT effects in patients with borderline LVEF, especially in non-coronary aetiology, have been discussed ${ }^{[13,14]}$. The presented findings stress that physicians should be aware of the diagnostic and decision-making efforts to provide CRT as optimally as possible for its expected and recommended results. Since CRT most often is an elective procedure, there is time to perform additional diagnostic procedures such as cardiac MRI or CT. Such methods may also clarify venous access and guide LV 
lead placement, thus ensuring that the patients get optimal results of CRT.

Limitations were typical for an observational registry study. Nevertheless, the significant number of recruited patients both in OEC and Poland may indicate high representativeness of the analysed data.

\section{Conclusions}

Echocardiographic left ventricular ejection fraction measurements determine CRT indication and are used in the vast majority of European, including Polish, patients, while the use of other methods such as MRI, CT and scintigraphy and the use of more than one method are visibly higher in other European countries than in Poland. CRT implantations are performed in a significant proportion of patients with left ventricular ejection fraction greater than or equal to $35 \%$.

\section{References}

1. 1. Ponikowski P, A. Voors A, Anker S, et al. 2016 ESC Guidelines for the diagnosis and treatment of acute and chronic heart failure. The Task Force for the diagnosis and treatment of acute and chronic heart failure of the European Society of Cardiology (ESC). Developed with the special contribution of the Heart Failure Association (HFA) of the ESC. European Heart Journal (2016) 37, 2141-2143.

2. Brignole $M$, Auricchio A, Baron-Esquivias G, et.al. 2013 ESC Guidelines on cardiac pacing and cardiac resynchronization therapy: the Task Force on cardiac pacing and resynchronization therapy of the European Society of Cardiology (ESC). Developed in collaboration with the European Heart Rhythm Association. Eur Heart J 2013;34:2299-2302.

3. Dickstein K, Normand C, Anker SD et al. European CRT Survey II, Rationale and design. Europace 2015 ;1:137-41.

4. Dickstein K, Normand C, Auricchio A, et. al. CRT Survey II: a European Society of Cardiology survey of cardiac resynchronisation therapy in 11 088 patients-who is doing what to whom and how? Eur J Heart Fail. 2018 Jun;20(6):1039-1051

5. Lang RM, Badano LP, Mor-Avi V, Afilalo J, Armstrong A, Ernande L, Flachskampf FA, Foster E, Goldstein SA, Kuznetsova T, Lancellotti P, Muraru D, Picard MH, Rietzschel ER, Rudski L, Spencer KT, TsangW, Voigt J-U. Recommendations for cardiac chamber quantification by echocardiography in adults: an update from the American Society of Echocardiography and the European Association of Cardiovascular Imaging. Eur Heart J Cardiovasc Imaging 2015;16: 233-270.
6. Linde CM, Daubert JC Abraham WT et al. on behalf of the REVERSE Study Group. Impact of cardiac resynchronization therapy in mild left ventricular systolic dysfunction. Results from the REsynchronization reverses Remodelling in Systolic left vEntricular dysfunction (REVERSE) study. Circulation Heart Failure 2013;6:1180-1189

7. Garbi M, McDonagh T, Cosyns B, Bucciarelli-Ducci C, Edvardsen T, Kitsiou A, Nieman K, Lancellotti P. Appropriateness criteria for cardiovascular imaging use in heart failure: report of literature review. Eur Heart J Cardiovasc Imaging 2015;16: 147-153.

8. Senges J. Initiative: The Institute for Myocardial Infarction Research Foundation Ludwigshafen. Circulation 2011;123:f136-f138.

9. Łasocha D, Sterliński M, Tajstra M et al. Do we differ in terms of indications and demographics in cardiac resynchronisation recipients in Poland? Insights from the European CRT Survey II Registry. Kardiol Pol. 2019;77(1):40-46. doi: 10.5603/KP.a2018.0215. Epub 2018 Nov 8.

10. Tajstra M, Łasocha D, Gadula-Gacek M et al. Cardiac resynchronization in Poland - comparable procedural routines? Insights from CRT Survey II. Adv Interv Cardiol 2019; 15, 4 (58): 477484. DOI: https://doi.org/10.5114/aic.2019.90223

11. Chung ES, Leon AR, Tavazzi L et al. Results of the Predictors of Response to CRT (PROSPECT) trial. Circulation. 2008 May 20;117(20):2608-16. doi: 10.1161/ CIRCULATIONAHA.107.743120. Epub 2008 May 5.

12. Van der Borgh T, Stegemann B, Sterliński M et al. Relation between left ventricular wall dimensions in cardiac resynchronization therapy candidates and echocardiographic and clinical outcome. Heart Beat 2017;2:27-32. DOI: https://doi.org/10.24255/hbj/81162

13. Barsheshet A, Moss AJ, Eldar M et al. Time-dependent benefit of preventive cardiac resynchronization therapy after myocardial infarction. Eur Heart J. 2011 Jul;32(13):1614-21. doi: 10.1093/eurheartj/ehq392. Epub 2010 Nov 12.

14. Køber L, Thune JJ, Nielsen JC et al. Defibrillator Implantation in Patients with Nonischemic Systolic Heart Failure. N Engl J Med. 2016 Sep 29;375(13):1221-30. doi: 10.1056/NEJMoa1608029. Epub 2016 Aug 27. 